\title{
SYNTHESIS AND CHARACTERIZATION OF NANOCRYSTALLINE CELLULOSE AS REINFORCEMENT IN NITRILE BUTADIENE RUBBER COMPOSITES
}

\author{
MOHAMAD NURUL AZMAN MOHAMMAD TAIB, WAGEEH A. YEHYE and \\ NURHIDAYATULLAILI MUHD JULKAPLI \\ Nanotechnology and Catalysis Research Centre (NANOCAT), Institute of Postgraduate Studies (IPS), \\ University of Malaya, 50603 Kuala Lumpur, Malaysia \\ \Corresponding author: Nurhidayatullaili Muhd Julkapli,nurhidayatullaili@um.edu.my
}

Received June 3, 2019

In this study, nanocrystalline cellulose (NCC) was produced with different concentrations of hydrochloric acid ( $\mathrm{HCl}$ ) and its surface charge, particle size, crystallinity and thermal properties were assessed. The obtained NCC was then used as reinforcement agent in nitrile butadiene rubber (NBR) composites. The NCC was found to have a particle size less than $100 \mathrm{~nm}$, with surface charge ranging from $-0.697 \mathrm{mV}$ to $-14.8 \mathrm{mV}$. The crystallinity index decreased to $64.78 \%$ for the NCC obtained with $6 \mathrm{M} \mathrm{HCl}$. The NCC synthesized with $1 \mathrm{M} \mathrm{HCl}$ showed the highest thermal stability, as demonstrated by TGA and DSC results. TEM analysis revealed that the NCC obtained with $5 \mathrm{M} \mathrm{HCl} \mathrm{had} \mathrm{the} \mathrm{smallest}$ particle size. The addition of different amounts of NCC into nitrile butadiene rubber (NBR) composites led to an enhancement of mechanical properties in terms of tensile strength, modulus and elongation at break up to the loading of $5 \mathrm{phr}$, but no substantial improvement in tear strength was noticed.

Keywords: nanocrystalline cellulose, acid hydrolysis, characterization, nanoparticle, mechanical properties

\section{INTRODUCTION}

Cellulose is a natural polysaccharide that is abundant in nature. Nanocrystalline cellulose (NCC) has many promising characteristics, such as high mechanical tensile strength $(0.3-22 \mathrm{GPa})$, high elastic modulus capacity (58-180 GPa), low density, biodegradability and non-toxicity, and due to this, NCC has become a topic of great research interest in recent years. The final properties of NCC are strongly dependent on its surface area, particle size, molecular weight and degree of crystallinity. ${ }^{1-4}$ Acid hydrolysis is one of the possible routes for NCC production, by reducing the cellulose chains. The use of hydrochloric acid $(\mathrm{HCl})$ in acid hydrolysis for NCC production has been reported to result in a significant increase in the active surface area and a smaller particle size of NCC, compared to that produced with other acid catalysts, including sulfuric acid, bromide acid and phosphoric acid. ${ }^{5-7}$ This is also supported by several studies that performed the hydrolysis of cellulose from different sources, such as cotton and kenaf fibers, using sulfuric and hydrochloric acid. ${ }^{8-10}$ The synthesis of $\mathrm{NCC}$ with $\mathrm{HCl}$ as a catalyst releases the hydronium $\left(\mathrm{H}^{+}\right)$ion for the hydrolytic cleavage of glycosidic bonds in the cellulosic molecular chains within the amorphous region.

In the acid hydrolysis process, different concentrations of the acid, temperatures and reaction time would lead to NCC with different crystallinity, particle size, molecular weight, yield, surface functionalization and geometry. ${ }^{11} \mathrm{~A}$ study by Bondeson et al. ${ }^{12}$ reported that using $\mathrm{H}_{2} \mathrm{SO}_{4}$ and two hours of hydrolysis time resulted in the production of NCC with $30 \%$ yield and with particle size ranging between $200 \mathrm{~nm}$ and $400 \mathrm{~nm}$.

In recent years, NCC has been investigated as a filler or reinforcement material in polymer matrices, including polyvinyl alcohol (PVA), polylactic acid (PLA), polyvinyl chloride (PVC) and natural rubber foam. ${ }^{13-17}$ However, no previous work has been reported on the 
application of NCC as a reinforcement in nitrile butadiene rubber (NBR). To date, various rubbers have been used to produce rubber gloves, for example, natural rubber and synthetic rubber, such as NBR. ${ }^{13}$ However, these materials, especially nitrile rubber, come with several drawbacks, including poor mechanical properties, conducing to susceptibility to being torn off, poor tensile properties, low robustness and nondegradability. To improve the mechanical properties of the rubber, the incorporation of fillers or reinforcement agents, including carbon black, silica, clay, rice bran carbon, nano- $\mathrm{Fe}_{3} \mathrm{O}_{4}$, zinc dimethacrylate, and other materials, has been investigated and it was demonstrated to enhance the rubber performance in terms of tear and tensile strength, hardness and degradability. ${ }^{18-22}$ However, the reinforcement with such fillers still presents some disadvantages, as the fillers used are not environmentally friendly. Also, the addition of nano- $\mathrm{Fe}_{3} \mathrm{O}_{4}$ leads to a decline in the modulus of elongation and tensile strength of the material. $^{22}$ Notably, NCC is a promising reinforcement agent due to its biological origin, its low density and non-toxicity.

In this study, NCC was produced by the acid hydrolysis method, and was then used as reinforcement of a NBR matrix. This study investigated the effect of different concentrations of $\mathrm{HCl}$ on the yield, morphology, crystallinity, thermal properties and active surface area of NCC. Furthermore, the NBR composites were evaluated in terms of mechanical properties and morphology. This study aims to gain knowledge regarding the effect of different concentrations of $\mathrm{HCl}$ on the properties of $\mathrm{NCC}$, and the influence of thus-produced NCC used reinforcement of NBR on the mechanical properties of the prepared composites.

\section{EXPERIMENTAL \\ Materials}

Commercially available cotton linter microcrystalline cellulose (MCC), with a diameter of $20 \mu \mathrm{m}$ and length of several micrometers, extracted from tunicin, $\mathrm{HCl}$ (37 wt\%), NBR latex (density 1.3 $\mathrm{g} / \mathrm{cm}^{3}$, solid content $43 \%$ ) and other chemicals were purchased from Friendemann Schmidt and local suppliers.

\section{Synthesis of NCC}

MCC (5 g) was manually added to different concentrations of $\mathrm{HCl}$ acid $(1 \mathrm{M}, 2 \mathrm{M}, 3 \mathrm{M}, 4 \mathrm{M}, 5 \mathrm{M}$ and $6 \mathrm{M})$. The MCC solution was then hydrolyzed at 100 ${ }^{\circ} \mathrm{C}$ for $60 \mathrm{~min}$, with continuous stirring $(500 \mathrm{rpm})$ in a conical flask. Then, the mixture was quenched in an ice tube to stop the reaction. The reaction mixture was rinsed with distilled water and centrifuged for $30 \mathrm{~min}$ at $3000 \mathrm{rpm}$. The supernatant was replaced by new distilled water and centrifuged again for five times. The product was then dialysed using a dialysis tube and immersed in distilled water (for ion exchange) until the $\mathrm{pH}$ of the water reached equilibrium at $\mathrm{pH} 7$. The resulting suspension was then freeze-dried and kept at room temperature until preparing the NBR matrix composites.

\section{Preparation of NBR/NCC composites}

SDBS (12.9 phr), ZDBC (2.58 phr), sulphur (5.02 phr), $\mathrm{ZnO}$ (4.66 phr) and $\mathrm{TiO}_{2}(6.45 \mathrm{phr})$ were mixed with $500 \mathrm{~mL}$ of NBR latex at room temperature. The mixture was left overnight under stirring. The total solid content was calculated and confirmed within $23 \%$ of the TSC target (distilled water was added in order to dilute the mixture solution until the TSC target was met). The $\mathrm{pH}$ was adjusted using an ammonia solution to achieve $\mathrm{pH} 9.0$ for preventing the latex from coagulating.

The NCC produced with $5 \mathrm{M}$ of $\mathrm{HCl}$ was chosen as the most suitable for preparing NBR/NCC composites. The desired content of dried NCC (from $1 \mathrm{phr}$ to $5 \mathrm{phr}$ ) was mixed with NBR latex and stirred vigorously (250 $\mathrm{rpm})$ at room temperature for $30 \mathrm{~min}$. The existing ammonia solution in the NBR prevented the latex from coagulating even though the latex was vigorously stirred. After that, the compounding of NBR/NCC with other ingredients was carried out in a beaker using a magnetic stirrer. The composite was prepared from the mixture of NBR and NCC using the dipping tank method. The NBR/NCC composite was cured in an oven at $125{ }^{\circ} \mathrm{C}$ for $20 \mathrm{~min}$. By modifying the contents of NCC over the range of 0-5 phr, a series of NBR composites with a thickness around $8 \mathrm{~mm}$ were prepared and denoted as NBR control, NBR/NCC 1 phr, NBR/NCC $2 \mathrm{phr}, \mathrm{NBR} / \mathrm{NCC} 3 \mathrm{phr}, \mathrm{NBR} / \mathrm{NCC} 4$ phr, and NBR/NCC $5 \mathrm{phr}$, respectively.

\section{Characterization \\ Yield percentage}

The yield of NCC was estimated as the weight of the oven dried NCC divided by the original weight of MCC before hydrolysis was conducted. The yield percentage of NCC was calculated by using Equation 1:

$$
Y=\frac{W n}{W p} x 100 \%
$$

where $Y$ is the NCC yield, $W n$ is the weight of NCC, and $W p$ is the weight of the MCC prior to hydrolysis.

\section{Particle size analysis}

Particle size analysis was conducted by dynamic light scattering (DLS) using a Zetasizer NanoZS Instrument (Malvern, UK) under the following conditions: dispersant water, material refractive index 
1.47, dispersion refractive index 1.33 , viscosity 0.8872 $\mathrm{cP}$ and temperature $25{ }^{\circ} \mathrm{C}$. The general calculation model was used for irregular particles. Three measurements of $12 \mathrm{~s}$ each were carried out to calculate an average of the particle size and surface area.

\section{Fourier transform infrared (FTIR) spectroscopy}

FTIR spectra were recorded on a Thermo Nicolet FTIR spectrometer (Nicolet 6700, USA) within the range of $400-4000 \mathrm{~cm}^{-1}$, at a spectral resolution of 4 $\mathrm{cm}^{-1}$; 32 scans of each sample were recorded. Each sample was palletized with $\mathrm{KBr}$ powder.

\section{X-ray diffraction (XRD) analysis}

$X$-ray diffraction (XRD) data were collected by an $\mathrm{X}$-ray diffractometer that was equipped with $\mathrm{Cu} \mathrm{K \alpha}$ radiation $(\lambda=0.1541 \mathrm{~nm})$ at the operating voltage and current of $45 \mathrm{kV}$ and $100 \mathrm{MA}$, respectively. Diffractograms were collected in the $2 \theta$ range of 5 40 at the rate of $1 \% \mathrm{~min}$ with a resolving power of $0.05^{\circ}$.

The crystallinity index was calculated according to Equation 2:

$$
\mathrm{CrI}=\frac{I_{002}-I_{\text {am }}}{I_{\text {goz }}} \times 100
$$

where $\mathrm{I}_{002}$ is the overall intensity of the peak at $2 \theta$ of about $22^{\circ}$ and $\mathrm{I}_{a m}$ is the intensity of the baseline at $2 \theta$ of about $18^{\circ}$.

The crystallite size (L) of NCC was calculated, by using Scherrer's equation, as shown in Equation 3:

$$
\mathbf{L}=\frac{K \lambda}{\beta \cos \theta}
$$

where $\mathrm{K}$ is a constant of value $0.94 ; \lambda$ is the $\mathrm{X}$-ray wavelength $(0.1542 \mathrm{~nm}) ; \beta$ is the half height weight of the diffraction band (FWHM is full width at half maximum); and $\theta$ is the Bragg angle corresponding to the (200) plane.

\section{Transmission electron microscopy (TEM) analysis}

Drops of $0.001 \%$ of NCC suspensions were deposited on glow-discharged carbon-coated TEM grids. The specimen was negatively stained with $2 \%$ uranyl acetate, prior to complete drying and observed using a Philips CM200 electron microscope, operating at $200 \mathrm{kV}$. Images were recorded on Kodak SO163 film.

\section{Thermogravimetry analysis (TGA)}

The thermogravimetric analysis (TGA) was conducted using a GA Q500 (TA instruments, USA). Approximately $5 \mathrm{mg}$ of sample was heated from $30^{\circ} \mathrm{C}$ to $600{ }^{\circ} \mathrm{C}$ at a heating rate of $10{ }^{\circ} \mathrm{C} / \mathrm{min}$ under nitrogen atmosphere.

\section{Differential scanning calorimetry (DSC) analysis}

DSC analysis was performed on a DSC-Q200 instrument under nitrogen atmosphere at a heating rate of $10{ }^{\circ} \mathrm{C} \mathrm{min}{ }^{-1}$ and flow rate of $50 \mathrm{~mL} / \mathrm{min}$. About 2 $\mathrm{mg}$ of each sample was placed in hermetically sealed
DSC crimp pans, which were tested over the temperature range from 25 to $450{ }^{\circ} \mathrm{C}$.

\section{Mechanical tests}

The tensile test was carried out by using a Universal Testing Machine. The samples were cut to dog bone shapes. All the experiments were carried out at room temperature with a crosshead speed of 500 $\mathrm{mm} / \mathrm{min}$ according to ASTM D412. The tear test was performed according to ASTM D624.

\section{Field emission scanning electron microscopy} (FESEM) analysis

The surfaces of the NBR/NCC composites were analyzed by a field emission scanning electron microscope (FESEM), at voltage acceleration of $5 \mathrm{kV}$ and low vacuum. Magnification of 10000x was used.

\section{RESULTS AND DISCUSSION Percentage yield, particle size distribution and zeta potential of NCC}

As the concentration of $\mathrm{HCl}$ was increased from $1 \mathrm{M}$ to $6 \mathrm{M}$, the total yield of NCC was significantly reduced from $93.94 \%$ to $73.24 \%$. Higher yield could be seen at a low acid concentration, while the diameter and length of NCC were higher and more diverse. Thus, the average yield of NCC was reduced with the increase in the acid concentrations from $1 \mathrm{M}$ of $\mathrm{HCl}(93.94 \%)$, to $2 \mathrm{M}(92.81 \%), 3 \mathrm{M}(88.34 \%)$, $4 \mathrm{M}(87.32 \%), 5 \mathrm{M}(82.50 \%)$ and $6 \mathrm{M}(73.24 \%)$, as shown in Figure 1. Due to the high acid concentration, the cellulose is fully depolymerized and converted into amorphous nanoparticles in water. ${ }^{23}$ At high acid concentration and temperature, the crystalline structure of NCC collapses and is reduced to sugars or further decomposition occurs into acid hydrolysis by-products. ${ }^{24}$

The particle size distribution and zeta potential results are also presented in Figure 1. The NCC synthesized using $1 \mathrm{M} \mathrm{HCl}$, produced with an average yield of $32.1 \%$, had a particle size around $141.8 \mathrm{~nm}$. No significant size reduction was recorded as the acid concentration was increased to $2 \mathrm{M}$. The particle size was reduced to $122.4 \mathrm{~nm}$ as the acid concentration was increased to $3 \mathrm{M}$. An approximately $43.5 \%$ yield of NCC was recorded at the acid concentration of $4 \mathrm{M}$, with a particle zise of $105.7 \mathrm{~nm}$. As the acid concentration was further increased to $5 \mathrm{M}$, it led to a yield of $32.4 \%$ and a particle size of $91.28 \mathrm{~nm}$, followed by a yield of $20.7 \%$ and a particle size of $164.2 \mathrm{~nm}$ at an acid concentration of $6 \mathrm{M}$. This is explained by the conversion of most of the cellulose particles to 
glucose (simple monomer units of cellulose), thus yielding NCC with a large diameter. Overall, these findings were in agreement with the results of FTIR and XRD analyses.

The surface charge of NCC decreased from $0.697 \mathrm{mV}$ to $-17.4 \mathrm{mV}$ with the increasing concentration of the acid, followed by a slight increase to $-14.8 \mathrm{mV}$ at $6 \mathrm{M}$ concentration of $\mathrm{HCl}$. It was also found that the suspension of NCC was considered unstable, with an absolute value lower than $-25 \mathrm{mV}$. At $5 \mathrm{M}$ concentration of $\mathrm{HCl}$, the surface charge was observed to drastically change from $-0.938 \mathrm{mV}$ to $-17.4 \mathrm{mV}$. The zero value of surface charge resulted in a higher tendency to form agglomerates between the NCC particles. Under normal conditions, a value lower than -15 $\mathrm{mV}$ indicates the onset of agglomeration, while a value higher than $-30 \mathrm{mV}$ indicates that sufficient mutual repulsion among particles, which results in colloidal stability. ${ }^{16}$ The $\mathrm{HCl}$ treated NCC crystals formed loose aggregates in water medium due to van der Waals forces and lack of surface charge of NCC. The interaction taking place among the colloidal particles in suspensions played an important role in determining the properties of NCC. These interactions involved intra/inter hydrogen bonding and van der Waals forces present among the polymeric chains. However, as the van der Waals interactions were weaker than the interactions between the hydrogen bonds, fluctuations in the distribution of the surface charge of NCC occurred. ${ }^{25,26}$ Intensive interaction among the particles of NCC led to the formation of loose and bulky aggregates in the molecular structure. Higher agglomeration was due to the surface charge, as shown in Figure 1. Thus, the $1 \mathrm{M}$ sample with $-0.697 \mathrm{mV}$ surface charge was

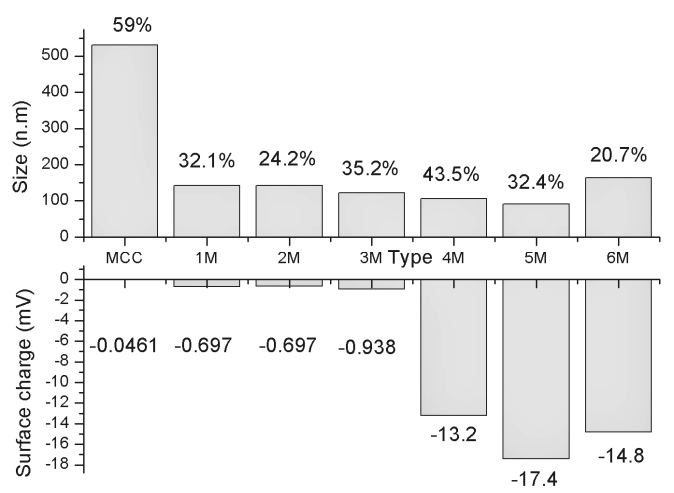

Figure 1: Percentage yield, particle size (above) and surface charge (below) of NCC at different concentrations of $\mathrm{HCl}(1 \mathrm{M}$ to $6 \mathrm{M})$ larger compared to the 5M sample. Nevertheless, no significant changes were observed in samples $1 \mathrm{M}$ and $2 \mathrm{M}$ in terms of surface charge, which contributed to insignificant changes in size distribution. Most of the reductions in surface charge led to notable changes in samples $3 \mathrm{M}$ to $5 \mathrm{M}$. Figure 2 illustrates the hydrogen bonding in NCC during the hydrolysis.

\section{Fourier transform infrared (FTIR) spectroscopy analysis}

Figure 3 (a) and Table 1 present the FTIR spectra of NCCs synthesized with different concentrations of $\mathrm{HCl}$ catalyst. A strong, broad peak is observed in the $3500 \mathrm{~cm}^{-1}$ region due to the $\mathrm{O}-\mathrm{H}$ bond stretching vibration. ${ }^{27}$ It is explained by the intra- and inter-hydrogen bonding of $\mathrm{NCCs}^{28} \mathrm{~A}$ significant increase in the peak intensity is noted with increasing $\mathrm{HCl}$ concentration from $1 \mathrm{M}$ to $5 \mathrm{M}$. This peak was then reduced at $6 \mathrm{M}$ concentration of $\mathrm{HCl}$ because of less surface activity. Excessive hydrolysis at a high concentration of acid led to the decomposition of NCC into glucose monomer units. The hydrolysis of MCC with $6 \mathrm{M}$ of $\mathrm{HCl}$ would lead to a small quantity of NCC produced, while the remaining $\mathrm{HCl}$ would be present in the glucose monomer. The active surface of NCC would be reduced, leading to the development of less active hydrogen bonds. The $\mathrm{C}-\mathrm{H}$ vibration is noted at $2900 \mathrm{~cm}^{-1}$, and is due to the presence of $\mathrm{CH}_{2}$ moieties in the NCC samples. The peak at $1644 \mathrm{~cm}^{-1}$ is associated with the $\mathrm{O}-\mathrm{H}$ bonding due to the moisture content of the sample.

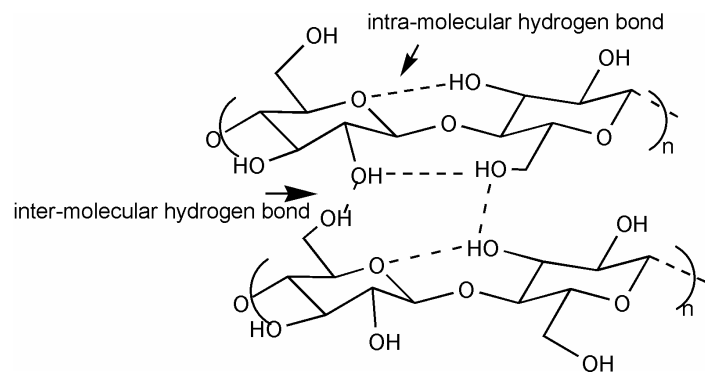

Figure 2: Hydrogen bonding between NCCs 
Nanocellulose

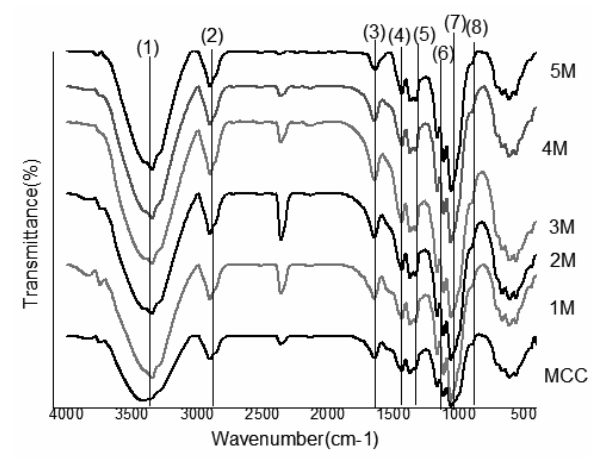

(a)

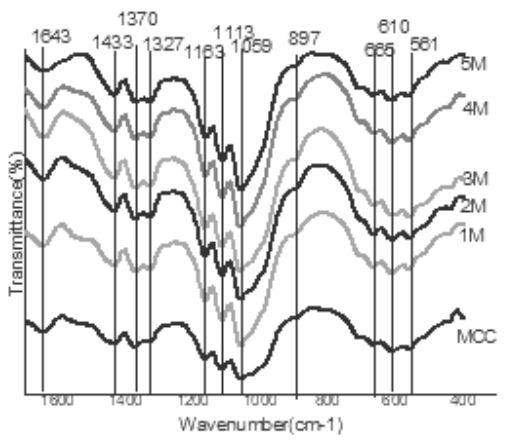

(b)

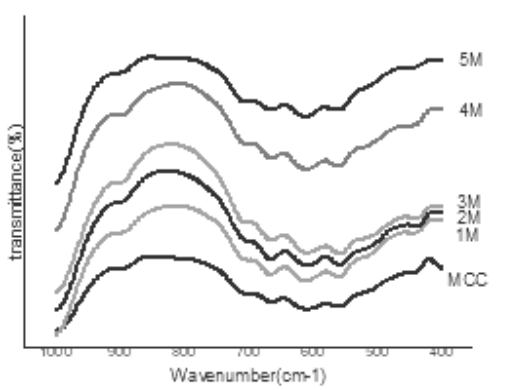

(c)

Figure 3: FTIR spectra of MCC and NCCs in different wavelength ranges, (a) $4000-400 \mathrm{~cm}^{-1}$; (b) $1700-400 \mathrm{~cm}^{-1}$; (c) $900-400 \mathrm{~cm}^{-1}$

Table 1

Infrared spectra with assignments of different peaks

\begin{tabular}{ccc}
\hline No & Peak position, $\mathrm{cm}^{-1}$ & Peak assignments \\
\hline 1 & $3416-3346$ & O-H stretching, vibration (hydrogen bonded) \\
2 & $2901-2904$ & C-H stretching vibration \\
3 & $1642-1644$ & Adsorbed water or moisture \\
4 & 1370 & C-H bending or assymetric C-H deformation \\
5 & $1327-1332$ & C-H deformation and C-OH deformation \\
6 & 1164 & C-O-C asymmetric valence vibration \\
7 & $1058-1059$ & C-O ether vibrations, methoxyl and $\beta-O-4$ \\
8 & 897 & C-H out of plane in position ring stretching in cellulose \\
& & due to $\beta$-linkage \\
\hline
\end{tabular}

Although the NCC samples were thoroughly dried using the freeze-drying method, the elimination of all moisture was a challenging process. Moreover, the presence of the peak at $1433 \mathrm{~cm}^{-1}$, which was due to $\mathrm{CH}_{2}$ bending motion in cellulose, suggested the intermolecular hydrogen attraction of the $\mathrm{C} 6$ group.

The peak at $1372 \mathrm{~cm}^{-1}$ for MCC then shifted to $1370 \mathrm{~cm}^{-1}$ after acid hydrolysis due to $\mathrm{C}-\mathrm{H}$ bending or asymmetric $\mathrm{C}-\mathrm{H}$ deformation of polysaccharides, while the peak at $1332 \mathrm{~cm}^{-1}$ for MCC shifted to $1329 \mathrm{~cm}^{-1}(1 \mathrm{M}), 1328 \mathrm{~cm}^{-1}$ (2M), $1328 \mathrm{~cm}^{-1}(3 \mathrm{M}), 1327 \mathrm{~cm}^{-1}(4 \mathrm{M})$, and $1327 \mathrm{~cm}^{-1}$ $(5 \mathrm{M})$. As a result of $\mathrm{CH}_{2}$ wagging, this peak shifted to a higher wavelength for sample $6 \mathrm{M}$ $\left(1335 \mathrm{~cm}^{-1}\right)$, leading to the decomposition of NCCs into a simple glucose monomer. Then, the peak at $1164 \mathrm{~cm}^{-1}$ indicates $\mathrm{C}-\mathrm{O}$ antisymmetric stretching, while that at $1115 \mathrm{~cm}^{-1}$, which is due to $\mathrm{C}-\mathrm{O}$ and $\mathrm{C}-\mathrm{C}$ stretching, shifted to a lower wavelength $\left(1113 \mathrm{~cm}^{-1}\right)$ after hydrolysis. A sharp peak is observed from $1053 \mathrm{~cm}^{-1}$ (MCC) to 1058 $\mathrm{cm}^{-1}(6 \mathrm{M})$ is due to the $\mathrm{C}-\mathrm{O}-\mathrm{C}$ pyranose ring stretching vibration. An increase in this band would be associated with an increase in the cellulose content, indicating lower cellulose content in the sample 6M. Also, all the samples showed the peak at $897 \mathrm{~cm}^{-1}$ associated with $\beta$ - 
glycosidic linkages consisting of $\mathrm{C}_{1}-\mathrm{H}$ and $\mathrm{O}-\mathrm{H}$ bending typical of the cellulose structure. In the case of the region around $900 \mathrm{~cm}^{-1}$ (Fig. 3 (c)), changes are noted as a function of the concentration of the acid from $1 \mathrm{M}$ to $6 \mathrm{M} \mathrm{HCl}$. This peak became sharper and narrower with the increase in the molar concentration of the acid, because of the reduction in the glycosidic linkage, as MCC was broken down to glucose units.

\section{X-ray diffraction (XRD) analysis}

The main peaks of all the samples were observed at 14.7, 16.6, 22.8, and $34.1^{\circ}$ (Fig. 4) due to the diffraction planes of (101), (10ī), (200) and (400), respectively. ${ }^{29}$ This pattern is similar to that of native cellulose or cellulose $\mathrm{I}^{30}$ Two distinct crystalline structures are formed in cellulose I, namely cellulose I $\alpha$ (triclinic) and cellulose I $\beta$ (monoclinic). The amount of the crystalline structure depends on the source of cellulose, while cellulose $\mathrm{I} \beta$ is usually dominant

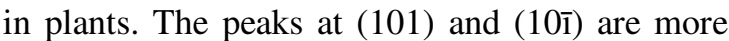
pronounced when the crystalline content is high, suggesting that acid hydrolysis using $\mathrm{HCl}$ had a limited effect on the polymorphism of cellulose I for the produced NCC samples.

Generally, the NCC produced by acid hydrolysis can have lower crystallinity. Furthermore, a high concentration of the acid would result in faster hydrolysis of NCC and thus a harsher one. The reduction in the diffraction intensities of the amorphous region is attributed to the less structured and bulky region of NCC polymeric chains. Moreover, the capacity of NCC to hold water depends on its crystallinity as the volume of bound water decreases with the increase in the degree of crystallinity within the NCC molecules. ${ }^{31,32}$ As seen in Figure 4, the Xray diffraction patterns reflect a decrease in the crystalline domains of the NCC as a function of acid concentration. This is proven by the significant decrease in the intensity of the diffraction peaks at $22.8^{\circ}$ for all the NCC samples. Based on the crystallinity index (CrI) of NCC shown in Table 2, the crystallinity of NCC was reduced with the increase in acid concentration from $1 \mathrm{M}$ to $6 \mathrm{M} \mathrm{HCl}$.

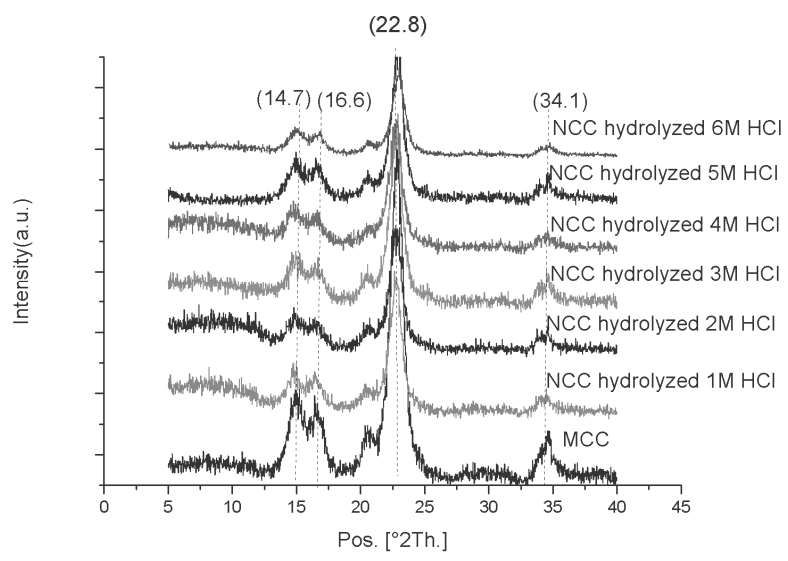

Figure 4: XRD patterns of MCC and NCCs (hydrolysed with $1 \mathrm{M}$ to $6 \mathrm{M} \mathrm{HCl}$ )

Table 2

Bragg angle, FWHM, crystalline size and crystallinity index of NCCs prepared with different acid concentration

\begin{tabular}{lcccc}
\hline Type of sample & $\begin{array}{c}\text { Bragg angle } \\
\text { (degree)/d-spacing }(\AA)\end{array}$ & $\begin{array}{c}\text { FWHM } \\
(\text { degree) }\end{array}$ & $\begin{array}{c}\text { Crystallinity } \\
\text { index }\end{array}$ & $\begin{array}{c}\text { Crystallite } \\
\text { size }(\mathrm{nm})\end{array}$ \\
\hline MCC & 3.864 & 0.984 & 69.49 & 8.2 \\
NCC hydrolyzed with 1M HCl & 3.878 & 0.984 & 73.89 & 8.2 \\
NCC hydrolyzed with 2M HCl & 3.888 & 0.984 & 71.40 & 8.2 \\
NCC hydrolyzed with 3M HCl & 3.880 & 0.984 & 72.15 & 8.2 \\
NCC hydrolyzed with 4M HCl & 3.883 & 0.984 & 71.03 & 8.2 \\
NCC hydrolyzed with 5M HCl & 3.896 & 1.181 & 70.50 & 6.9 \\
NCC hydrolyzed with 6M HCl & 3.901 & 1.808 & 64.78 & 4.5 \\
\hline
\end{tabular}


Nanocellulose

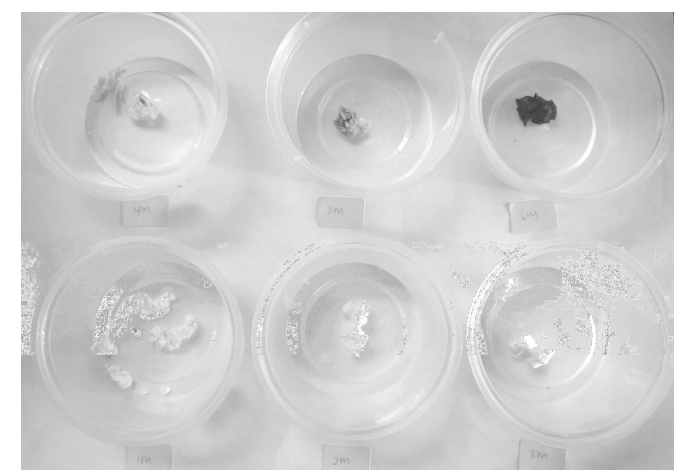

Figure 5: Color changes of NCCs after treatment with different acid concentrations from $1 \mathrm{M}$ to $6 \mathrm{M} \mathrm{HCl}$

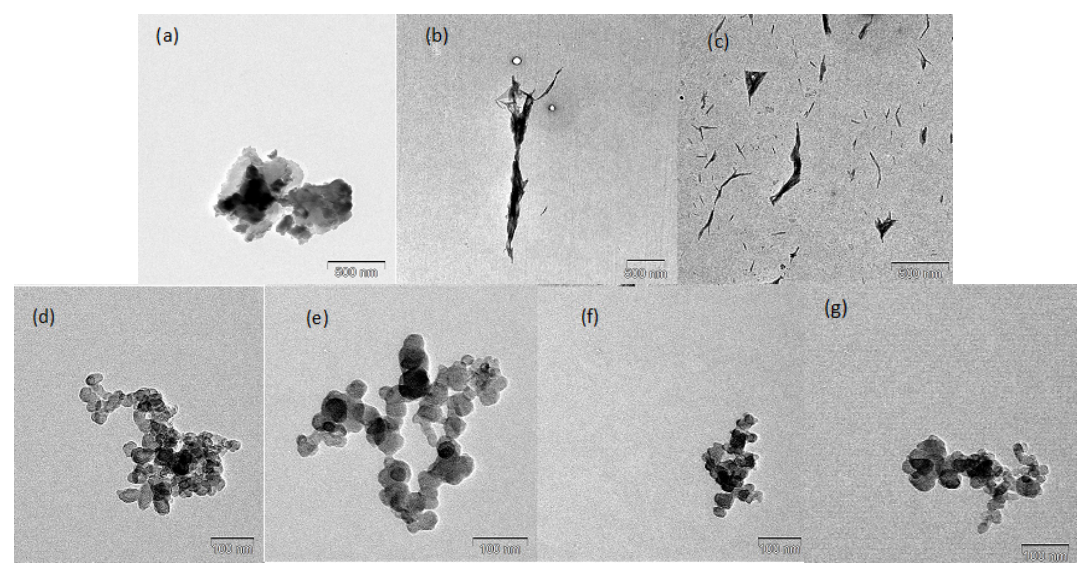

Figure 6: TEM images of (a) MCC (500 nm), (b) $1 \mathrm{M}(500 \mathrm{~nm})$, (c) $2 \mathrm{M}(500 \mathrm{~nm})$, (d) $3 \mathrm{M}(100 \mathrm{~nm})$, (e) $4 \mathrm{M}(100 \mathrm{~nm})$, (f) $5 \mathrm{M}(100 \mathrm{~nm}),(\mathrm{g}) 6 \mathrm{M}(100 \mathrm{~nm})$

Figure 5 illustrates the changes in color from that of MCC to those of NCC treated with different contrations of $\mathrm{HCl}$. Specifically, the darker color indicates the burning of NCC and its concersion into simple glucose units. This supports the choice of the acid concentration of $5 \mathrm{M} \mathrm{HCl}$ as an optimized condition for the production of NCC. The successive removal of the amorphous region was observed during this reaction. At high temperature, the reaction occurred in the amorphous region at a higher rate, cleaving the $\beta-1,4$-glycosidic linkages by maintaining unaltered the crystallite segments. ${ }^{33,34}$ The amorphous part was preferentially cleaved, while the crystalline regions were resistant to acid attack and mostly remained intact during hydrolysis.

However, the increase in acid concentration from $2 \mathrm{M}$ to $5 \mathrm{M}$ led to a slight decrease of the crystallinity index because of partial destruction of the crystalline structure and production of more disordered regions in nanocellulose. Further decrease in crystallinity was observed at $5 \mathrm{M}$ and $6 \mathrm{M} \mathrm{HCl}$ concentrations, which was proportional to the decrease in the crystal size. At $6 \mathrm{M} \mathrm{HCl}$, the crystallinity index and crystallite size were reduced to 64.78 and $4.5 \mathrm{~nm}$, respectively, because of extensive degradation of NCC caused by the high concentration of $\mathrm{HCl}$, while most NCCs were converted into glucose. This finding is in agreement with those reported in a previous study by Li et al. ${ }^{35}$

\section{Transmission electron microscopy (TEM) analysis}

Transmission electron micrographs of MCC and NCCs synthesized with different concentration levels of $\mathrm{HCl}$ are presented in Figure 6. As may be noted in Figure 6a, the MCC has large dimensions and particles are contoured from dark color to white. Specifically, the dark color indicates a thicker structure, compared to the white one, due to agglomeration of MCC. Meanwhile, based on Figure $6 \mathrm{~b}$ and Figure $6 \mathrm{c}$, 
which present needle-like and narrow shapes, it can be concluded that the treatment with $1 \mathrm{M}$ and $2 \mathrm{M} \mathrm{HCl}$ would hydrolyze MCC into NCC, with a variety of sizes and shapes. The treatment with $3 \mathrm{M} \mathrm{HCl}$ (Fig. 6d) modified the NCCs produced to smaller particulate sizes, with no significant variation. The difference in the NCC shapes is observed when comparing the NCCs produced with $1 \mathrm{M}$ to $6 \mathrm{M}$ acid catalyst concentration.

Further observation was conducted on the platelet-like particles of the NCC, those achieved at higher concentration levels of the acid (Figs. 6 (d-g)). After hydrolysis, the NCC was found to aggregate due to the hydrogen bond interactions via the surface hydroxyl groups. Moreover, the effect of the interfacial interaction and bonding could be amplified in the NCC particles with a larger specific surface area. The specific surface area increases with a rising aspect ratio or reduced diameter of NCC. The NCC that has a larger surface to volume ratio is more suitable for application in reinforcing composites as it can provide more contact surface and improved surface reactivity towards the polymer matrix, effectively preventing polymer chains mobility. ${ }^{36}$ Due to increased interfacial interaction, improved properties of composites, with the use of low filler conten, could be predicted. However, due to the highly hydrophilic nature of cellulose, NCC particles with high surface area might attract surrounding nano-sized particles, forming agglomerates. ${ }^{11}$ When aggregation occurs, redispersing the NCC would be a challenging process, thus such particles would not be suitable for reinforcement purposes, without any modification treatment or functionalization.

\section{Thermogravimetry analysis (TGA)}

Figure 7 and Figure 8 illustrate the TG and DTG thermograms of MCC and NCCs produced with various $\mathrm{HCl}$ concentration levels. The degradation patterns were quite similar for all the samples. As shown in Figure 7a, the first weight loss occurred at a temperature $<100{ }^{\circ} \mathrm{C}$. All the samples, from MCC to NCCs, demonstrated a small weight loss in this region due to the evaporation of absorbed water (Fig. 7b). As may be noted, as an effect of excessive hydrolysis, the NCC produced with $6 \mathrm{M}$ HCL was mostly converted into glucose monomer and had high amorphous content; therefore, it had a higher tendency to absorb moisture and thus presented higher weight loss. This finding was in agreement with the report of Mariano et al. ${ }^{37}$
The region ranging from $100{ }^{\circ} \mathrm{C}$ to $200{ }^{\circ} \mathrm{C}$ demonstrated constant weight for the different types of NCCs. The degradation onset temperature was recorded at $322{ }^{\circ} \mathrm{C}$ for MCC, it slightly increased to $327{ }^{\circ} \mathrm{C}$ for $1 \mathrm{M} \mathrm{HCl}$ hydrolyzed NCC, then decreased to $324{ }^{\circ} \mathrm{C}$, and remained constant for the NCCs obtained with 2 $\mathrm{M}, 3 \mathrm{M}, 4 \mathrm{M}$ and $5 \mathrm{M} \mathrm{HCl}$. Subsequently, the onset temperature dropped to $320{ }^{\circ} \mathrm{C}$ for the NCC treated with $6 \mathrm{M} \mathrm{HCl}$. For all the samples, from MCC and the whole range of NCCs, the dominant peak was recorded between $300{ }^{\circ} \mathrm{C}$ and $350{ }^{\circ} \mathrm{C}$, a temperature range where degradation processes, such as depolymerization, dehydration and decomposition of glycosidic linkage and rings, take place. The decomposition that occurred beyond $350{ }^{\circ} \mathrm{C}$ consisted in the oxidation and breakdown of the charred residue into gaseous products with low molecular weight.

It was reported by Zhou et al..$^{38}$ that the decomposition temperature of cellulose ranges from $315{ }^{\circ} \mathrm{C}$ to $400{ }^{\circ} \mathrm{C}$, which is in line with the findings of this study. Lower onset was reported by Flauzino et al., ${ }^{39}$ who performed the conversion of MCC to nanocrystals with sulfuric acid. They explained the lower onset as being caused by the presence of sulfate groups on the cellulose surface, which had a catalytic effect on the thermal degradation of cellulose. Moreover, the decomposition at a lower temperature would also result in a faster transfer of heat in the samples. Subsequently, a difference in the amount of weight loss occurred, indicating the degradation of the samples started within the heating region. As seen in the final degradation stage at $400{ }^{\circ} \mathrm{C}$, the $\mathrm{MCC}$ weight loss only remained at $17.08 \%$, compared to the other samples. Specifically, the NCCs synthesised with $1 \mathrm{M}, 2 \mathrm{M}, 3 \mathrm{M}, 4 \mathrm{M}, 5 \mathrm{M}$ and $6 \mathrm{M}$ acid recorded $15.32 \%, 14.80 \%, 14.26 \%, 14.25 \%, 12.26 \%$ and $14.97 \%$ respectively. The highly crystalline structure of NCCs was a key factor in the thermal stability of the samples, as the cellulose chains remained in a highly ordered formation through strongly stabilized hydrogen bonding. ${ }^{3}$ The formation of highly ordered three-dimensional crystal structures is considered to lead to high thermal stability, as the interchain hydrogen bonds in the crystalline regions are not easily dissociated by high temperature, preventing the cellulose from degradation. ${ }^{40}$

The DTG thermograms in Figure $8(a, b)$ illustrate that the maximum peaks exhibited by MCC reached $348{ }^{\circ} \mathrm{C}$, while those of NCC 
reached $352{ }^{\circ} \mathrm{C}(1 \mathrm{M} \mathrm{HCl}), 349^{\circ} \mathrm{C}(2 \mathrm{M} \mathrm{HCl}), 348$ ${ }^{\circ} \mathrm{C}(3 \mathrm{M} \mathrm{HCl}), 349^{\circ} \mathrm{C}(4 \mathrm{M} \mathrm{HCl}), 348^{\circ} \mathrm{C}(5 \mathrm{M} \mathrm{HCl})$ and $345{ }^{\circ} \mathrm{C}(6 \mathrm{M} \mathrm{HCl})$. The highest thermal stability was exhibited by the NCC hydrolyzed with $1 \mathrm{M} \mathrm{HCl}$, as shown by its highest temperature peak.

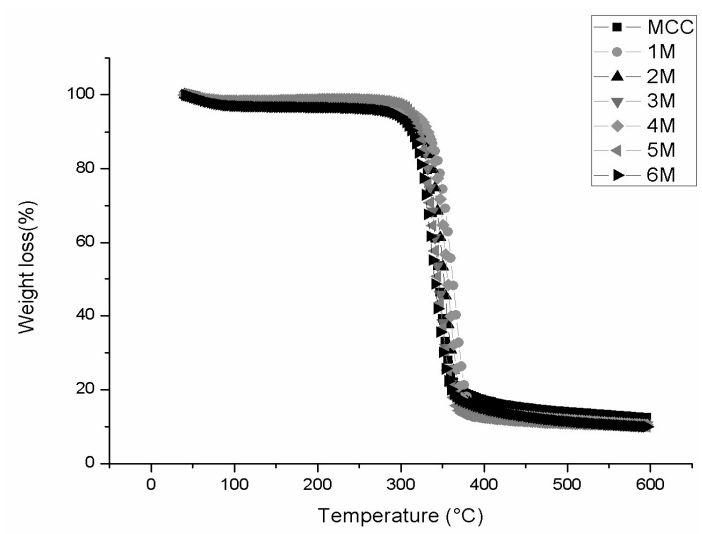

a)

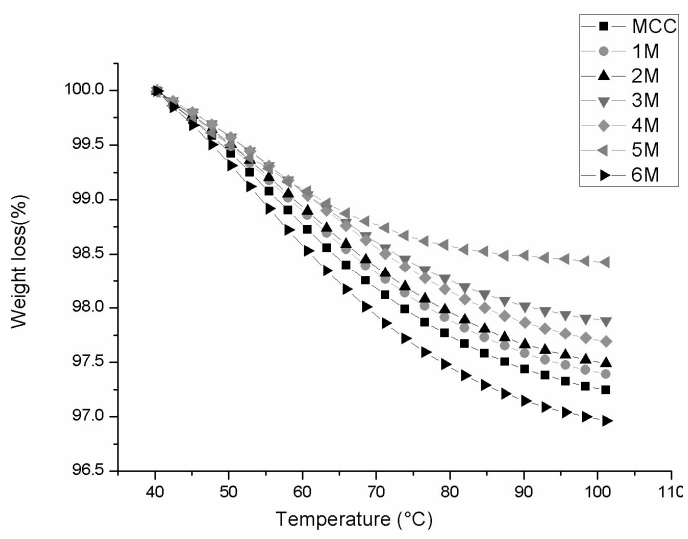

b)

Figure 7: TG curves for NCC samples $\left(30-600{ }^{\circ} \mathrm{C}\right)(\mathrm{a})$ and their magnification in the region $0-100{ }^{\circ} \mathrm{C}(\mathrm{b})$

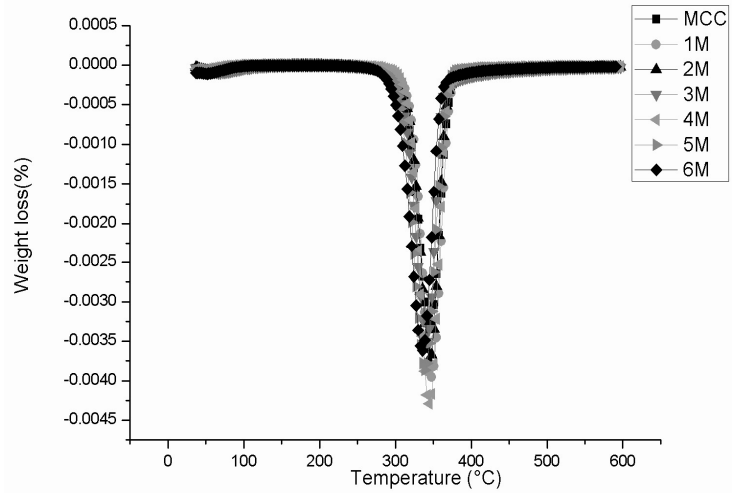

a)

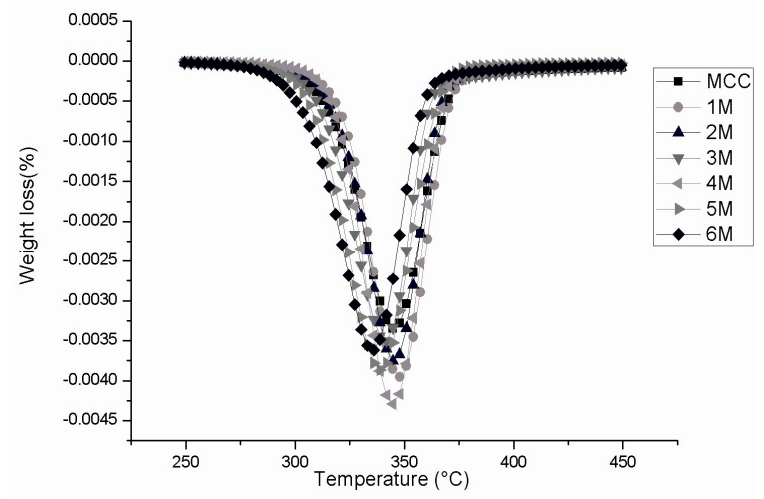

b)

Figure 8: DTG curves for NCC samples $\left(30-600{ }^{\circ} \mathrm{C}\right)$ (a) and their magnification in the region $250-410{ }^{\circ} \mathrm{C}$ (b)

Table 3

Thermal degradation parameters of different NCC samples

\begin{tabular}{lcccc}
\hline Sample type & $\begin{array}{c}\text { Onset } \\
\text { temperature }\left({ }^{\circ} \mathrm{C}\right)\end{array}$ & $\begin{array}{c}\text { Weight loss } \\
(\%)\end{array}$ & $\begin{array}{c}\mathrm{T}_{\max } \\
\left({ }^{\circ} \mathrm{C}\right)\end{array}$ & $\begin{array}{c}\text { Char yield } \\
(\%)\end{array}$ \\
\hline MCC & 322 & 96.50 & 348 & 12.47 \\
NCC hydrolyzed with 1M HCl & 327 & 96.50 & 352 & 11.43 \\
NCC hydrolyzed with 2M HCl & 324 & 96.79 & 349 & 11.22 \\
NCC hydrolyzed with 3M HCl & 324 & 98.04 & 348 & 10.42 \\
NCC hydrolyzed with 4M HCl & 324 & 97.01 & 349 & 10.40 \\
NCC hydrolyzed with 5M HCl & 324 & 98.01 & 348 & 10.06 \\
NCC hydrolyzed with 6M HCl & 320 & 97.52 & 345 & 10.01 \\
\hline
\end{tabular}

Note: $\mathrm{T}_{\max }$ : degradation temperature from DTG curve, and char at $600{ }^{\circ} \mathrm{C}$

The amount of char residue was reduced with the increase in molar concentration of the acid used during the hydrolysis process. As shown in Table 3, the amount of char for MCC was $12.47 \%$, and it decreased to $11.43 \%$ for $1 \mathrm{M}, 11.22 \%$ for
$2 \mathrm{M}, 10.42 \%$ for $3 \mathrm{M}, 10.4 \%$ for $4 \mathrm{M}, 10.06 \%$ for $5 \mathrm{M}$ and $10.01 \%$ for $6 \mathrm{M} \mathrm{HCl}$. Insignificant differences in the amount of char residue are noted among the samples treated with $3 \mathrm{M}$ and $4 \mathrm{M}$ $\mathrm{HCl}$. 
The reduction in the char residue, with an increased molar concentration of $\mathrm{HCl}$, for the NCC samples, can be explained by increased hydrogen bonding, which was broken down through acid hydrolysis. The split in hydrogen bonding would contribute to the formation of larger surface area, which could easily be degraded by the thermal reaction. ${ }^{41}$ In another study, by Meyabadi et al..${ }^{10}$ it was reported that the amount of charred residue was higher in samples with higher crystallinity. The increase in the concentration of $\mathrm{HCl}$ would provide more $\mathrm{H}^{+}$, which would strengthen the catalytic reaction of the glycosidic bonds between the nanocrystalline cellulose chains. This mechanism of hydrogen bond splitting is illustrated in Figure 9.

\section{Differential scanning calorimetry (DSC) analysis}

Figure 10 illustrates the DSC of MCC and NCCs hydrolyzed different concentrations of $\mathrm{HCl}$. The DSC patterns appear to be similar for all the samples. The first endotherm took place in the temperature range from $33^{\circ} \mathrm{C}$ to $118^{\circ} \mathrm{C}$ for $\mathrm{MCC}$, from $31{ }^{\circ} \mathrm{C}$ to $113{ }^{\circ} \mathrm{C}(1 \mathrm{M})$, from $32^{\circ} \mathrm{C}$ to $116^{\circ} \mathrm{C}$ (2M), from $34{ }^{\circ} \mathrm{C}$ to $116{ }^{\circ} \mathrm{C}(3 \mathrm{M})$, from $34{ }^{\circ} \mathrm{C}$ to $114{ }^{\circ} \mathrm{C}(4 \mathrm{M})$, from $34{ }^{\circ} \mathrm{C}$ to $109{ }^{\circ} \mathrm{C}(5 \mathrm{M})$, and from $41{ }^{\circ} \mathrm{C}$ to $116^{\circ} \mathrm{C}(6 \mathrm{M})$ for the NCCs obtained with different concentrations of $\mathrm{HCl}$. The endotherm in this range was the result of water evaporation or degradation of low molecular weight and amorphous components. ${ }^{42}$ The rearrangement of molecular chains of the amorphous component would increase the endotherms transition. ${ }^{43}$ Meanwhile, the second endotherm transition occurred in the temperature range from $312{ }^{\circ} \mathrm{C}$ to $362{ }^{\circ} \mathrm{C}$ for $\mathrm{MCC}$, and from $333{ }^{\circ} \mathrm{C}$ to $369{ }^{\circ} \mathrm{C}(1 \mathrm{M})$, from $320{ }^{\circ} \mathrm{C}$ to $355{ }^{\circ} \mathrm{C}$ (2M), from $314{ }^{\circ} \mathrm{C}$ to $351{ }^{\circ} \mathrm{C}(3 \mathrm{M})$, from $309{ }^{\circ} \mathrm{C}$ to $353{ }^{\circ} \mathrm{C}(4 \mathrm{M})$, from $310^{\circ} \mathrm{C}$ to $351{ }^{\circ} \mathrm{C}(5 \mathrm{M})$, and from $299{ }^{\circ} \mathrm{C}$ to $317{ }^{\circ} \mathrm{C}(6 \mathrm{M})$ for the NCCs hydrolyzed with different concentrations of $\mathrm{HCl}$. This endotherm transition could be attributed to the decomposition of the crystalline part of NCC. In the case of the NCC, this region corresponded to the melting temperature where the separation of glycosidic bonds and the depolymerization of cellulose chains occur. ${ }^{43}$ A sharp endothermic peak in this region is assigned to the fusion of the crystalline parts, the peak of MCC reaching 322 ${ }^{\circ} \mathrm{C}$, while those of the NCCs $-355{ }^{\circ} \mathrm{C}(1 \mathrm{M}), 339$ ${ }^{\circ} \mathrm{C}(2 \mathrm{M}), 333{ }^{\circ} \mathrm{C}(3 \mathrm{M}), 334{ }^{\circ} \mathrm{C}(4 \mathrm{M}), 331{ }^{\circ} \mathrm{C}$ $(5 \mathrm{M})$, and $327{ }^{\circ} \mathrm{C}(6 \mathrm{M} \mathrm{HCl})$. The decrease in the peak temperature in this region could be explained by the increase in the amorphous content and the reduction in the cellulose crystallite size. ${ }^{42}$

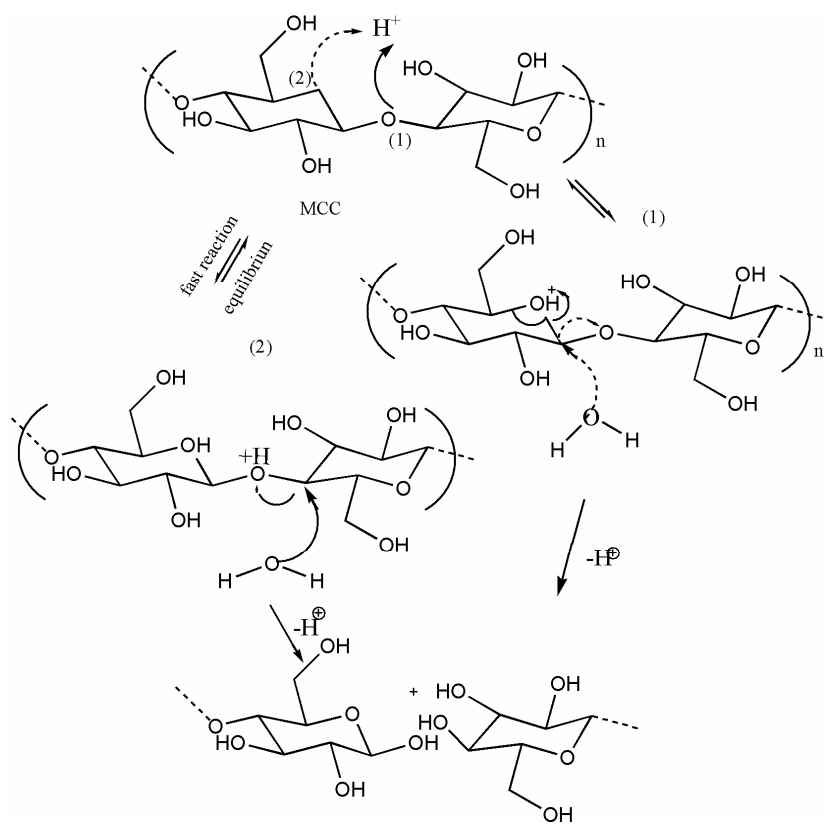

Figure 9: Acid hydrolysis mechanism ${ }^{11}$ 


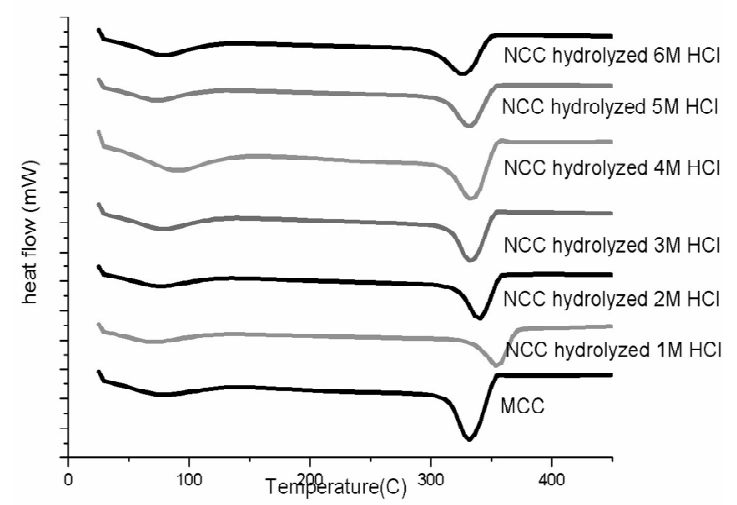

Figure 10: DSC curves of MCC and NCCs

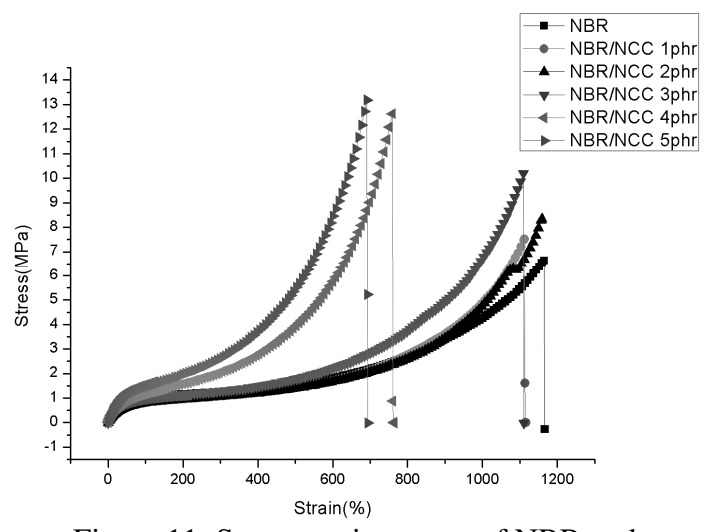

Figure 11: Stress-strain curves of NBR and NBR/NCC composites

Table 4

Mechanical properties of NCC reinforced NBR composites

\begin{tabular}{ccccccc}
\hline $\begin{array}{c}\text { NCCs } \\
\text { content } \\
(\mathrm{phr})\end{array}$ & $\begin{array}{c}\text { Tensile } \\
\text { strength } \\
(\mathrm{MPa})\end{array}$ & $\begin{array}{c}\text { Modulus at } \\
100 \% \text { strain } \\
(\mathrm{MPa})\end{array}$ & $\begin{array}{c}\text { Modulus at } \\
300 \% \text { strain } \\
(\mathrm{MPa})\end{array}$ & $\begin{array}{c}\text { Modulus at } \\
500 \% \text { strain } \\
(\mathrm{MPa})\end{array}$ & $\begin{array}{c}\text { Elongation } \\
\text { at break } \\
(\%)\end{array}$ & $\begin{array}{c}\text { Tear strength } \\
(\mathrm{kN} / \mathrm{m})\end{array}$ \\
\hline 0 & $8.264(1.07)$ & $1.057(0.18)$ & $1.346(0.28)$ & $1.680(0.48)$ & $3.457(0.65)$ & $15.008(1.85)$ \\
1 & $8.780(0.78)$ & $0.871(0.08)$ & $1.213(0.09)$ & $1.646(0.12)$ & $2.937(0.32)$ & $14.714(1.23)$ \\
2 & $7.259(1.46)$ & $0.840(0.03)$ & $1.106(0.04)$ & $1.402(0.06)$ & $2.807(0.14)$ & $14.808(1.61)$ \\
3 & $9.105(2.15)$ & $0.983(0.06)$ & $1.272(0.09)$ & $1.674(0.11)$ & $3.315(0.23)$ & $14.020(0.78)$ \\
4 & $13.608(1.65)$ & $1.173(0.04)$ & $1.909(0.07)$ & $3.392(0.14)$ & $3.504(0.13)$ & $13.106(0.74)$ \\
5 & $16.588(3.06)$ & $1.597(0.11)$ & $2.753(0.22)$ & $5.408(0.42)$ & $4.539(0.34)$ & $15.458(1.21)$ \\
\hline
\end{tabular}

Note: Standard deviations are shown in brackets

\section{Mechanical properties}

The stress-strain curves of the NBR/NCC composites are illustrated in Figure 11, while the mechanical performance of the composites is demonstrated in Table 4. Notably, the stress-strain curves shown in Figure 11 are similar to the pattern observed by Kumagai et al. ${ }^{44}$ The increase in stress was due to the strain-induced crystallization at a higher strain level in the composite. Further improvement could be seen from the tensile strength result with the addition of $1 \mathrm{phr}$ to $5 \mathrm{phr}$ NCC to the NBR composites.

Compared to the control NBR, a slight decrease in the composite containing $2 \mathrm{phr}$ NCC was due to the incompatibility or agglomeration of NCC in the NBR matrix, although this decrease was not significant. Moreover, the tensile strength for the $4 \mathrm{phr}$ and $5 \mathrm{phr}$ composite samples was more significant, compared to the tensile strength of the NBR control sample. Although the mean of the $5 \mathrm{phr}$ sample was the highest, there was no substantial difference between the mean of the 5 phr and that of the $4 \mathrm{phr}$ samples.

When comparing the tensile strength of the $\mathrm{NBR} / \mathrm{NCC}$ composites designed in this study for manufacturing rubber gloves with that of commercial gloves made from the fully synthetic $\mathrm{NBR}$, the minimum tensile strength for the commercial product is $22 \mathrm{MPa}$, which is higher than the tensile strength the composites in our study. Also, Chen et al. ${ }^{13}$ reported on foamed nitrile rubber reinforced with cellulose nanocrystals, suggesting that the $15 \mathrm{phr}$ cellulose nanocrystals was the optimum value to fill in nitrile foam rubber to achieve a tensile strength of 6.54 MPa. As foamed rubber consists of a high quantity of voids, it was suggested that better mechanical properties of foamed rubbers could be achieved through smaller foam size. It was also proposed by Chen et al. ${ }^{13}$ and Cao et al. ${ }^{45}$ that low loadings of the NCC filler in the matrix could improve the mechanical properties of rubber composites.

The effects of filler loading on the modulus at 100\% elongation (M100) are illustrated in Table 4. It may be noted that M100 increased with rising NCC content from $1 \mathrm{phr}$ to $5 \mathrm{phr}$. The increase in M100 for the $1 \mathrm{phr}$ to $5 \mathrm{phr}$ samples was due to the improvement in the cross-linking of the NBR matrix with NCC. The incorporation of NCCs into the NBR matrix increased the stiffness of the material and thus the tensile modulus. Notably, 
better dispersion could enhance the interfacial adhesion between the NCCs and the NBR matrix. Based on the morphological study, it was suggested that the NCC developed interfacial bonding with the NBR matrix. However, compared to the neat NBR (control), no significant increment in the modulus at $300 \%$ and $500 \%$ strain was noted in the samples containing $1 \mathrm{phr}$ to $3 \mathrm{phr}$ NCC. Meanwhile, the value of the modulus at $300 \%$ and $500 \%$ strain for commercial gloves amounts to $0.8 \mathrm{MPa}$ and $1.5 \mathrm{MPa}$, respectively, and thus, compared to them, the NBR/NCC composites in this study reached higher values for both moduli, and for both the increment was proportional with the addition of NCC to NBR. The incorporation of $1 \mathrm{phr}$ to $3 \mathrm{phr}$ NCC led to minor effects on the cross-linking with the NBR network, therefore, no improvement was achieved. However, a significant increment is noted upon NCC addition of $4 \mathrm{phr}$ and $5 \mathrm{phr}$, due to the strong network interaction developed between the rubber and the filler. The tensile strength and modulus of elasticity were higher than those of NBR upon the addition of $4 \mathrm{phr}$ and more filler. As the elastic modulus represents the ability of materials to resist deformation, the increase in the elastic modulus of the composites indicated stronger resistance to deformation. ${ }^{46}$

Table 4 illustrates the elongation at break for NBR and NBR composites at different filler loadings. Based on the results in Table 4 , it could be seen that the $5 \mathrm{phr}$ NCC loading led to the highest elongation at break, while the 2 phr one showed the lowest elongation at break. The addition of $5 \mathrm{phr}$ filler could improve the elongation at break of NBR, due to improved cross-linking between NBR and NCC. No significant difference can be seen for the $1 \mathrm{phr}$ to 4 phr loadings, when compared to NBR (control), as at these loadings the agglomeration of NCCs in the matrix occurred because of the strong hydrogen bonding between the NCCs. As a result, a brittle composite was formed, with low elongation at break. Overall, this finding is in agreement with Venugopal et al., ${ }^{47}$ who concluded that agglomeration at higher loadings impacted tensile strength and tear strength. The flexibility and elasticity of the rubber chains were restricted when the NCCs were incorporated into the NBR matrix, leading to a more rigid rubber matrix and to a reduction of the elongation at break. Nevertheless, the tear strength results in Table 4 were not significantly different with the increase in the NCC loading. Upon comparison with commercial gloves $(54 \mathrm{kN} / \mathrm{m})$, the results obtained indicate that the tear strength of NBR/NCC composites was lower than that of commercial gloves. The addition of NCC could not stop the propagation of cracks, initiated by the tearing force. The interaction mechanism of NCC and NBR is illustrated in Figure 12.

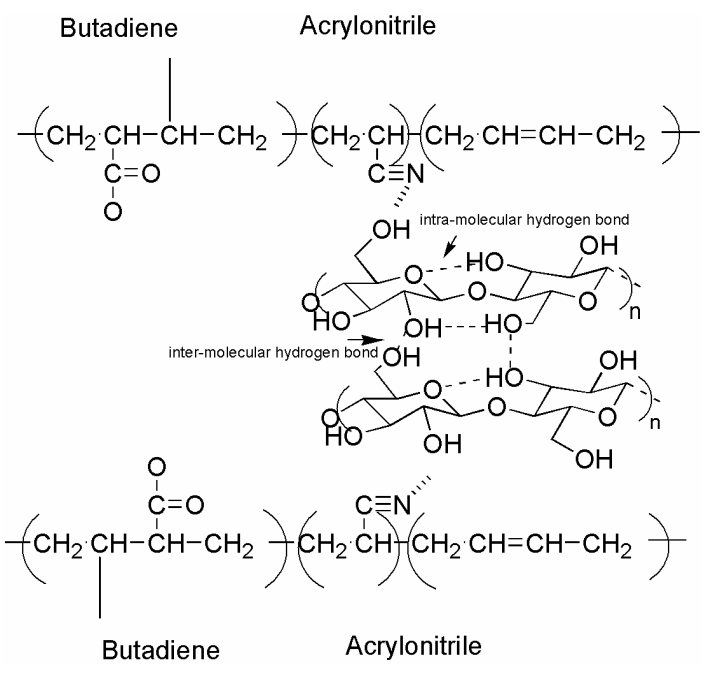

Figure 12: Interaction of NCC with NBR matrix 


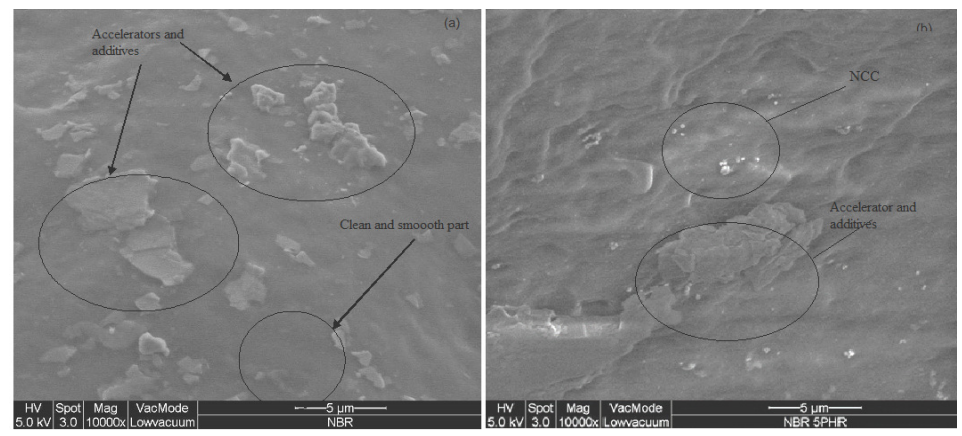

Figure 13: FESEM images of (a) NBR control and (b) NBR/NCC composites at 5 phr filler loading

\section{Morphological study by Field Emission Scanning Electron Microscopy (FESEM) analysis}

Figure 13 presents images of the surface of the neat NBR and the composite with 5 phr loading. In Figure 13 (a), the micrograph illustrates the surface of the neat NBR, indicating strong interfacial adhesion and effective wetting in the rubber blend. The unmodified NBR taken as a control sample presents a smooth surface, with some protruding elements, possibly originating from the accelerator and additives.

After NBR was reinforced with NCC, some NCC particles are observed represented by white dots. Increased NCC loading is conducive to the aggregation or agglomeration of NCC particles and leads to poor dispersion in the NBR matrix, which resulted in poor performance of the material. Also the hydrophilic/hydrophobic difference of NCC and NBR would result in incompatibility problems. Such incompatibility could affect the performance of NBR composites, when the NCC is incorporated at higher loading. Thus, uniform distribution of the filler within the matrix would create further crosslinking between the NCCs and the NBR, while, in contrast, the agglomeration of the filler and its poor distribution in the matrix could deteriorate the interfacial adhesion and bonding within the composites produced.

\section{CONCLUSION}

NCC was successfully extracted through the hydrolysis of commercial microcrystalline cellulose cotton linter. The effect of $\mathrm{HCl}$ concentration on the yield percentage, particle size, functional groups, crystallinity and thermal stability of NCC was studied. It was found that, although the yield percentage was reduced with increased concentration of the acid, it also impacted the size of the NCC produced. Moreover, the crystallinity of NCC exhibited reduction at higher $\mathrm{HCl}$ concentrations, because of the separation of the glycosidic linkage and the decrease in crystallite size. Consequently, the thermal stability of the NCC produced with higher concentration of $\mathrm{HCl}$ was lower. Considering all the parameters, it was considered that the optimum acid condition for hydrolysis was $5 \mathrm{M}$ $\mathrm{HCl}$.

Based on the analysis of the composite materials prepared by incorporating NCCs with different loadings, it was found that the tensile strength exhibited a significant improvement in the materials containing up to $5 \mathrm{phr}$ NCC loading. The tensile modulus at $100 \%, 300 \%, 500 \%$ strain, and the elongation at break improved with the incorporation of NCC as a filler. In conclusion, the reinforcement of NBR composites with NCC can improve the mechanical performance of the composites.

ACKNOWLEDGEMENTS: The authors would like to thank the University of Malaya for providing financial support of this project. This project was financially supported by Postgraduate Research Grant (PPP) (PG238-2015A: Effects on surface acetylated nanocrystalline cellulose (NCC) reinforced in nitrile butadiene rubber (NBR) composite) and SATU Research Grant 2019 (ST011:2019 Development of biodegradable and high strength composites).

\section{REFERENCES}

1 S. Elazzouzi-Hafraoui, Y. Nishiyama, J.-L. Putaux, L. Heux, F. Dubreuil et al., Biomacromolecules, 9, 57 (2007), https://doi.org/10.1021/bm700769p 2 B. Peng, N. Dhar, H. Liu and K. Tam, Can. J. Chem. Eng., 89, $1191 \quad$ (2011), https://doi.org/abs/10.1002/cjce.20554 
3 S. Rebouillat and F. Pla, J. Biomater. Nanobiotechnol., $\quad \mathbf{4}, \quad 165 \quad$ (2013), https://doi.org/10.4236/jbnb.2013.42022

4 K.-Y. Lee, Y. Aitomäki, L. A. Berglund, K. Oksman and A. Bismarck, Compos. Sci. Technol., 105, 15

https://doi.org/10.1016/j.compscitech.2014.08.032

5 M. L. Yan, S. J. Li, M. X. Zhang, C. J. Li, F. Dong et al., Bioresources, 8, $6330 \quad$ (2013), https://ncsu.edu/bioresources/BioRes_08/BioRes_08_4 _6330_Yan_LZLDL_Charac_Acetylated_NCC_Single Step_3771.pdf

6 Y. J. Tang, S. J. Yang, N. Zhang and J. H. Zhang, Cellulose, 21, 335 (2014), https://doi.org/10.1007/s10570-013-0158-2

7 H. Sadeghifar, I. Filpponen, S. P. Clarke, D. F. Brougham and D. S. Argyropoulos, J. Mater. Sci., 46, 7344 (2011), https://doi.org/10.1007/s10853-0115696-0

8 H. Kargarzadeh, I. Ahmad, I. Abdullah, A. Dufresne, S. Zainudin et al., Cellulose, 19, 855 (2012), https://doi.org/10.1007\%2Fs10570-012-9684-6

9 L. H. Zaini, M. Jonoobi, P. M. Tahir and S. Karimi, J. Biomater. Nanobiotechnol., 4, 37 (2013), https://doi.org/10.4236/jbnb.2013.41006

10 T. F. Meyabadi, F. Dadashian, G. M. M. Sadeghi and H. E. Z. Asl, Powder Technol., 261, 232 (2014), https://doi.org/10.1016/j.powtec.2014.04.039

11 P. Lu and Y.-L. Hsieh, Carbohyd. Polym., 82, 329 (2010), https://doi.org/10.1016/j.carbpol.2010.04.073

12 D. Bondeson, A. Mathew and K. Oksman, Cellulose, $\quad 13, \quad 171 \quad$ (2006), https://doi.org/10.1007/s10570-006-9061-4

13 Y. Chen, Y. Zhang, C. Xu and X. Cao, Carbohyd. Polym., 130, 149 (2015), https://doi.org/10.1016/j.carbpol.2015.05.017

14 B. Schyrr, S. Pasche, G. Voirin, C. Weder, Y. C. Simon et al., ACS Appl. Mater. Interfaces, 6, 12674 (2014), https://doi.org/10.1021/am502670u

15 S.-Y. Lee, D. J. Mohan, I.-A. Kang, G.-H. Doh, S. Lee et al., Fiber. Polym., 10, 77 (2009), https://doi.org/10.1007/s12221-009-0077-x

16 J. Trifol, D. Plackett, C. Sillard, O. Hassager, A. E. Daugaard et al., J. Appl. Polym. Sci., 133, 43257 (2016), https://doi.org/10.1002/app.43257

17 Y. Zhou, S. Fu, L. Zheng and H. Zhan, Express Polym. Lett., $\quad$ 6, $794 \quad$ (2012), https://doi.org/10.3144/expresspolymlett.2012.85

18 C. H. Xu, Y. K. Chen, Y. P. Wang and X. R. Zeng, Polym. Compos., 32, $2084 \quad$ (2011), https://doi.org/10.1002/pc.21239

19 A. Mostafa, A. Abouel-Kasem, M. R. Bayoumi and M. G. El-Sebaie, Mater. Des., 30, 2721 (2009), https://doi.org/10.1016/j.matdes.2008.09.045

20 S. I. Volfson, N. A. Okhotina, A. I. Nigmatullina and O. A. Panfilova, AIP Conf. Proc., 1599, 418 (2014), https://doi.org/10.1063/1.4876867
21 S. H. Xu, J. Gu, Y. F. Luo, D. M. Jia and L. Yan, Polym. Compos., 36, $861 \quad$ (2015), https://doi.org/10.1002/pc.23005

22 Q. L. Wang, F. Y. Yang, Q. Yang, J. H. Chen and H. Y. Guan, Mater. Des., 31, 1023 (2010), https://doi.org/10.1016/j.matdes.2009.07.038

${ }^{23}$ Y. F. Liu, H. S. Wang, G. Yu, Q. X. Yu, B. Li et al., Carbohyd. Polym., 110, $415 \quad$ (2014), https://doi.org/10.1016/j.carbpol.2014.04.040

24 D. Qiang, M. Zhang, J. Li, H. Xiu and Q. Liu, Cellulose, 23, 1199 (2016), https://doi.org/10.1007/s10570-016-0858-5

25 C. Salas, T. Nypelo, C. Rodriguez-Abreu, C. Carrillo and O. J. Rojas, Curr. Opin. Colloid Interface Sci., 19, $383 \quad$ (2014), https://doi.org/10.1016/j.cocis.2014.10.003

26 S. M. Notley, B. Pettersson and L. Wagberg, J. Am. Chem. Soc., 126, 13930 (2004), https://doi.org/10.1021/ja045992d

27 A. R. Nair, S. Sambhudevan and B. Shankar, Cellulose Chem. Technol., 53, 263 (2019), https://www.cellulosechemtechnol.ro/pdf/CCT34(2019)/p.263-270.pdf

28 V. Hospodarova, E. Singovszka and N. Stevulova, Am. J. Anal. Chem., 9, 303 (2018), https://doi.org/10.4236/ajac.2018.96023

29 P. Mansikkamäki, M. Lahtinen and K. Rissanen, Carbohyd. Polym., 68, $35 \quad$ (2007), https://doi.org/10.1016/j.carbpol.2006.07.010

30 S. Park, J. O. Baker, M. E. Himmel, P. A. Parilla and D. K. Johnson, Biotechnol. Biofuels, 3, 10 (2010), https://doi.org/10.1186/1754-6834-3-10

31 K. Nakamura, T. Hatakeyama and H. Hatakeyama, Text. Res. J., 51, $607 \quad$ (1981), https://doi.org/10.1177/004051758105100909

32 A. Espert, F. Vilaplana and S. Karlsson, Compos. A-Appl. Sci. Manuf., 35, $1267 \quad$ (2004), https://doi.org/10.1016/j.compositesa.2004.04.004

${ }_{33}$ W. Chen, H. Yu, Y. Liu, P. Chen, M. Zhang et al., Carbohyd. Polym., 83, $1804 \quad$ (2011), https://doi.org/10.1016/j.carbpol.2010.10.040

${ }^{34}$ X. Y. Tan, S. B. Abd Hamid and C. W. Lai, Biomass Bioenerg., 81, $584 \quad$ (2015), https://doi.org/10.1016/j.biombioe.2015.08.016

35 J. Li, X. Zhang, M. Zhang, H. Xiu and H. He, BioResources, 9, 1334 (2014), https://ncsu.edu/bioresources/

36 M. Minelli, M. G. Baschetti, F. Doghieri, M. Ankerfors, T. Lindström et al., J. Membrane Sci., 358, 67

(2010),

https://doi.org/10.1016/j.memsci.2010.04.030

37 M. Mariano, N. El Kissi and A. Dufresne, Carbohyd. Polym., 137, $174 \quad$ (2016), https://doi.org/10.1016/j.carbpol.2015.10.027

${ }^{8}$ L. Zhou, H. He, C. Jiang, Li Ma and P. Yu, Cellulose Chem. Technol., 51, 109 (2017), http://www.cellulosechemtechnol.ro/pdf/CCT12(2017)/p.109-119.pdf 
39 W. P. Flauzino Neto, M. Mariano, I. Souza Vieira da Silva, H. Alves Silvério, J.-L. Putaux et al., Carbohyd. Polym., 153, $143 \quad$ (2016), https://doi.org/10.1016/j.carbpol.2016.07.073

${ }^{40}$ G. H. D. Tonoli, E. M. Teixeira, A. C. Corrêa, J. M. Marconcini, L. A. Caixeta et al., Carbohyd. Polym., 89, 80 (2012), https://doi.org/10.1016/j.carbpol.2012.02.052

${ }_{41}$ Y. Tang, X. Shen, J. Zhang, D. Guo, F. Kong et al., Carbohyd. Polym., 125, $360 \quad$ (2015), https://doi.org/10.1016/j.carbpol.2015.02.063

42 J. I. Morán, V. A. Alvarez, V. P. Cyras and A. Vázquez, Cellulose, 15, $149 \quad$ (2008), https://doi.org/10.1007/s10570-007-9145-9

43 L. C. Yeng, M. U. Wahit and N. Othman, J. Teknol., $\quad \mathbf{7 5}, \quad 107 \quad$ (2015), https://doi.org/10.11113/jt.v75.533843
44 A. Kumagai, N. Tajima, S. Iwamoto, T. Morimoto, A. Nagatani et al., Int. J. Biol. Macromol., 121, 989 (2019), https://doi.org/10.1016/j.ijbiomac.2018.10.090 ${ }^{45}$ X. Cao, C. Xu, Y. Wang, Y. Liu, Y. Liu et al.,

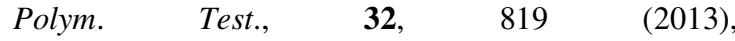
https://doi.org/10.1016/j.polymertesting.2013.04.005

${ }^{46}$ X. Xiong, Y. Bao, H. Liu, Q. Zhu, R. Lu et al., Mater. Chem. Phys., 223, 535 (2019), https://doi.org/10.1016/j.matchemphys.2018.11.041

47 B. Venugopal and G. Joyalatha, Mater. Today: $\begin{array}{llll}\text { Proc., } & \text { 5, } & 16724 & \text { (2018), }\end{array}$ https://doi.org/10.1016/j.matpr.2018.06.036 